\title{
Is persistent hypotension after transient cardiogenic shock associated with an inflammatory response?
}

\author{
M. Park ${ }^{1,2}$, A.T. Maciel ${ }^{1,2}$, D.T. Noritomi ${ }^{1,2}$, M.K. Brunialtit ${ }^{3}$, R. Salomão ${ }^{3}$, \\ G.P.P. Schettino ${ }^{1}$ and L.C.P. Azevedo ${ }^{1,2}$
}

${ }^{1}$ Laboratório de Pesquisa em Medicina Intensiva e Anestesiologia, Instituto de Ensino e Pesquisa, Hospital Sírio-Libanês, São Paulo, SP, Brasil

2Unidade de Terapia Intensiva, Disciplina de Emergências Clínicas, Hospital das Clínicas, Faculdade de Medicina, Universidade de São Paulo, São Paulo, SP, Brasil

${ }^{3}$ Laboratório de Imunologia, Departamento de Moléstias Infecciosas, Universidade Federal de São Paulo, São Paulo, SP, Brasil

Correspondence to: M. Park, Rua Francisco Preto, 46, Bloco 3, Apto. 64, 05323-010 São Paulo, SP, Brasil

E-mail: mpark@uol.com.br

\begin{abstract}
We evaluated the recovery of cardiovascular function after transient cardiogenic shock. Cardiac tamponade was performed for $1 \mathrm{~h}$ and post-shock data were collected in 5 domestic large white female pigs ( $43 \pm 5 \mathrm{~kg})$ for $6 \mathrm{~h}$. The control group ( $\mathrm{N}=5)$ was observed for $6 \mathrm{~h}$ after $1 \mathrm{~h}$ of resting. During $1 \mathrm{~h}$ of cardiac tamponade, experimental animals evolved a low perfusion status with a higher lactate level $(8.0 \pm 2.2$ vs $1.9 \pm 0.9 \mathrm{mEq} / \mathrm{L})$, lower standard base excess $(-7.3 \pm 3.3$ vs $2.0 \pm 0.9 \mathrm{mEq} / \mathrm{L})$, lower urinary output $\left(0.9 \pm 0.9\right.$ vs $\left.3.0 \pm 1.4 \mathrm{~mL} \cdot \mathrm{kg}^{-1} \cdot \mathrm{h}^{-1}\right)$, lower mixed venous saturation, higher ileum partial pressure of $\mathrm{CO}_{2}$-end tidal $\mathrm{CO}_{2}$ $\left(\mathrm{EtCO}_{2}\right)$ gap and a lower cardiac index than the control group. Throughout the 6-h recovery phase after cardiac tamponade, tamponade animals developed significant tachycardia with preserved cardiac index, resulting in a lower left ventricular stroke work, suggesting possible myocardial dysfunction. Vascular dysfunction was present with persistent systemic hypotension as well as persistent pulmonary hypertension. In contrast, oliguria, hyperlactatemia and metabolic acidosis were corrected by the 6 th hour. The inflammatory characteristics were an elevated core temperature and increased plasma levels of interleukin-6 in the tamponade group compared to the control group. We conclude that cardiovascular recovery after a transient and severe low flow systemic state was incomplete. Vascular dysfunction persisted up to $6 \mathrm{~h}$ after release of tamponade. These inflammatory characteristics may also indicate that inflammatory activation is a possible pathway involved in the pathogenesis of cardiogenic shock.
\end{abstract}

Key words: Cardiogenic shock; Cardiac tamponade; Systemic inflammatory response syndrome; Swine; Myocardial dysfunction; Inflammation

Research supported by Instituto de Ensino e Pesquisa, Hospital Sírio-Libanês, São Paulo, SP, Brasil. Publication supported by FAPESP.

Received December 3, 2007. Accepted June 24, 2008

\section{Introduction}

Cardiogenic shock is an important cause of death, particularly in patients with acute coronary syndromes $(1,2)$. In spite of the large number of treatment strategies that have been tested (3-8), mortality remains high (9) and thus far only a strategy associated with early myocardial revascularization has improved the outcome (6).

There are few studies addressing the late response of the cardiovascular system after a transient hypotensive episode of cardiac origin. In fact, most of cardiogenic and obstructive shock studies have emphasized the shock period with few or no data on the recovery phase (10). A transient cardiac-induced hypotensive episode could be 
assumed to represent a global ischemia-reperfusion scenario and, as such, be associated with alterations of vascular function, even after recovery from shock.

A new paradigm in the pathophysiology of cardiogenic shock has related this disease to the development of systemic inflammatory response syndrome (SIRS) (11). According to this hypothesis, in addition to the normal pathophysiologic process, cardiogenic shock could be associated with the generation of inflammatory mediators in the circulation, as well as an overproduction of nitric oxide (NO) through inducible nitric oxide synthase (NOS) (2). This would lead to vascular dysfunction and therefore increase mortality (12). However, the validity of this hypothesis has not been proven. In some studies, a great subgroup of patients with cardiogenic shock and inflammatory response were previously submitted to surgical revascularization, which could have caused systemic inflammatory response per se (11). In addition, experimental and clinical data also failed to demonstrate any benefit in unspecific blockade of NOS in acute heart failure and cardiogenic shock $(5,13)$.

Thus, the aim of this study was to evaluate, in an experimentally controlled setting, the recovery of the cardiovascular system after a severe cardiac tamponadeinduced systemic low-flow state for up to $6 \mathrm{~h}$ after tamponade relief. A second aim was to determine if a transient episode of hypotension was associated with the development of systemic inflammation.

\section{Material and Methods}

This study had previous approval from the Institutional Animal Research Ethics Committee of Hospital Sírio Libanês (São Paulo, SP, Brazil) and was performed according to National Institutes of Health (USA) guidelines for the use of experimental animals.

\section{Instrumentation and stabilization period}

Ten domestic large white female pigs with a body weight of $43 \pm 5 \mathrm{~kg}$ were fasted overnight before the experiment with free access to water. Animals were premedicated with an intramuscular injection of midazolam

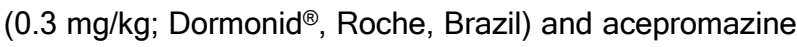
(0.5 mg/kg; Acepran ${ }^{\circledR}$, Andrômaco, Brazil). Through an auricular vein, anesthesia was induced with thionembutal (12 mg/kg; Tiopental ${ }^{\circledR}$, Abbott, Brazil) and muscular relaxation with pancuronium bromide $\left(0.1 \mathrm{mg} / \mathrm{kg}\right.$; Pavulon ${ }^{\circledR}$, AKZO Nobel, Brazil). They were then submitted to endotracheal intubation and connected to a mechanical ventilator (Evita 2, Drager, Germany) with the following parameters: tidal volume of $8-10 \mathrm{~mL} / \mathrm{kg}$, end-expiratory pressure of $5 \mathrm{~cm} \mathrm{H}_{2} \mathrm{O}$, inspiratory fraction of oxygen adjusted to keep arterial saturation between 94 and $96 \%$, and respiratory rate necessary to keep $\mathrm{PaCO}_{2}$ between 35 and $45 \mathrm{mmHg}$. After the end of instrumentation and respiratory parameters have been reached, no alterations of ventilatory parameters were allowed throughout the study. Anesthesia was maintained during the study period with midazo$\operatorname{lam}\left(0.3 \mathrm{mg} \cdot \mathrm{kg}^{-1} \cdot \mathrm{h}^{-1}\right)$, fentanyl citrate $\left(5 \mu \mathrm{g} \cdot \mathrm{kg}^{-1} \cdot \mathrm{h}^{-1} ;\right.$ Fentanil $^{\circledR}$, Janssen-Cilag, Brazil) and muscular relaxation with pancuronium bromide $\left(0.2 \mathrm{mg} \cdot \mathrm{kg}^{-1} \cdot \mathrm{h}^{-1}\right)$. Supplementary bolus of $5 \mu \mathrm{g} / \mathrm{kg}$ fentanyl citrate and $0.1 \mathrm{mg} / \mathrm{kg}$ pancuronium bromide were administered, if necessary.

The right external jugular vein was dissected and cannulated for introduction of a catheter that was guided to the pulmonary artery by visualization of pressure curves. The right femoral artery was dissected and cannulated and a catheter was inserted to measure continuous arterial pressure and to collect arterial samples. Cystostomy was performed through an inferior laparotomy and a bladder catheter was inserted to measure urinary output. Venous oximetry was calibrated in vivo with a mixed venous sample gas analysis obtained from the distal port of the pulmonary arterial catheter.

After monitorization, boluses of $250 \mathrm{~mL}$ lactated Ringer's solution were used to keep a systemic mean arterial blood pressure $(A B P m) \geq 100 \mathrm{mmHg}$, central venous pressure (CVP) $\geq 8 \mathrm{mmHg}$ and mixed venous saturation $\left(\mathrm{SvO}_{2}\right)$ $\geq 70 \%$ until the end of instrumentation. After the hemodynamic goals were achieved, amiodarone $(5 \mathrm{mg} / \mathrm{kg}$ ) was infused for $60 \mathrm{~min}$ in both groups to prevent life-threatening arrhythmias associated with balloon inflation identified in previous pilot experiments. A midline laparotomy was performed, a tonometry catheter was inserted in the terminal ileum and the spleen was removed to avoid autotransfusion during shock (14-16). Through the laparotomy incision, a diaphragmatic window was opened and the heart and mediastinum were dissected from the sternum, a plastic catheter with a rubber balloon was inserted through the diaphragmatic window, and fixed with a wood stem. Then, the laparotomy was closed. After instrumentation, an infusion of $5 \mathrm{~mL} \cdot \mathrm{kg}^{-1} \cdot \mathrm{h}^{-1}$ lactated Ringer's solution was started and maintained for all animals throughout the experiment to avoid hypovolemia. The animals were then allowed to stabilize without any intervention for $1 \mathrm{~h}$.

ABPm, CVP and pulmonary artery pressure (PAPm) were measured with quartz transducers (Edwards Critical Care, USA) and displayed continuously on a multi-modular monitor (DX 2020, Dixtal, Brazil). Heart rate was measured with an electrocardiogram, oximetry was placed on the tail of the animals and end tidal $\mathrm{CO}_{2}\left(\mathrm{EtCO}_{2}\right)$ sensor was connected to a line-stream system placed between the 
tracheal tube and the $Y$ piece of the ventilator. All these measurements were obtained with a DX 2020 multi-modular monitor. Continuous central venous oximetry was measured by spectrophotometry and continuous cardiac output was measured by thermodilution (Vigilance ${ }^{\circledR}$, Edwards Lifesciences, USA). Central temperature was obtained from the thermistor in the pulmonary artery catheter. Ileum regional $\mathrm{CO}_{2}$ partial pressure was obtained using a $14 \mathrm{~F}$ tonometry catheter (Tonometrics ${ }^{\circledR}$, Datex-Ohmeda, USA) and a tonometry monitor (Tonocap ${ }^{\circledR}$, Datex-Ohmeda).

\section{Shock period}

After the stabilization period, 5 animals were randomly allocated to have the cardiac balloon inflated until systemic ABPm was between 45 and $55 \mathrm{mmHg}$. Variations of 10-50 $\mathrm{mL}$ of cardiac balloon volume were permitted in order to maintain systemic ABPm within the pre-specified range for $1 \mathrm{~h}$. Randomization was performed using a box with ten envelopes in a 5:5 allocation scheme. Animals allocated to the control group were maintained for one additional hour in observation.

Before cardiac balloon inflation, hemodynamic data [heart rate, cardiac output, PAPm, ABPm, CVP, pulmonary artery occlusion pressure (PAOP), $\mathrm{SvO}_{2}$, urinary output, ileum regional $\mathrm{CO}_{2}$ partial pressure, $\mathrm{EtCO}_{2}$, core temperature, arterial blood samples and arterial lactate were collected and recorded as baseline data. During the 1-h shock period, heart rate, cardiac output, PAPm, ABPm, $\mathrm{CVP}, \mathrm{SvO}_{2}$, ileum regional $\mathrm{CO}_{2}$ partial pressure, and $\mathrm{EtCO}_{2}$ were collected every $10 \mathrm{~min}$ in the shock group. After $1 \mathrm{~h}$ of cardiogenic shock-induced hypotension, the cardiac balloon was deflated. Five minutes after cardiac balloon deflation, the same variables were measured again and recorded as post-shock results. In the control group, data were collected at baseline and post-shock.

\section{Post-shock and 6-h observation period}

After the shock period, animals were observed for $6 \mathrm{~h}$ to characterize this period regarding hemodynamic, metabolic and inflammatory variables. Hemodynamic data (heart rate, cardiac output, PAPm, ABPm, CVP, PAOP), ileum regional $\mathrm{CO}_{2}$ partial pressure, EtCO 2 , core temperature, arterial blood sample and arterial lactate were collected at 1,3 , and $6 \mathrm{~h}$ after cardiac balloon deflation. Urinary output was measured at the end of each hour. Blood samples were obtained to measure interleukin- 6 concentrations at baseline, 3 and $6 \mathrm{~h}$ and stored at $-80^{\circ} \mathrm{C}$ until laboratory measurement. At the end of the 6th hour, a thoracotomy was performed, heart and lungs were macroscopically inspected and animals were then sacrificed with an intravenous bolus injection of $20 \mathrm{~mL}$ potassium chloride.

\section{Laboratory analysis}

Blood gas, hemoglobin (used in the mixed venous hemoglobin saturation monitor calibration), standard base excess and lactate analysis were performed in a blood gas analyzer (ABL 700 Radiometer, Denmark). Cytokine concentration in plasma was measured with specific commercially available enzyme-linked immunosorbent assay kits according to manufacturer instructions (R\&D Systems, USA).

\section{Calculations}

To calculate hemodynamic variables extracted from the pulmonary artery catheter monitorization, standard formulas were used (17). Parameters whose units are not given in the tables are as follows: a) systemic vascular resistance index (dynes $\left.\mathrm{s}^{-1} \cdot\left(\mathrm{cm}^{5}\right)^{-1} \cdot \mathrm{kg}^{-1}\right)=(\mathrm{ABPm}-\mathrm{CVP}) \mathrm{x}$ 80 / Cl; b) left ventricular stroke work index $[(\mathrm{mL} \times \mathrm{mmHg})$ $/(\mathrm{kg} \times$ beat $)]=(\mathrm{ABPm}-\mathrm{PAOP}) \times \mathrm{SI} \times 0.0136$, where $\mathrm{SI}=$ stroke index and $\mathrm{Cl}=$ cardiac index.

\section{Statistical analysis}

Data were considered to be normal using the ShapiroWilk goodness of fit model, and are reported as mean \pm standard deviation. Single means were compared with the Student $t$-test and a $\mathrm{P} \leq 0.05$ was considered to be significant. Means within groups and between groups as well as the factor $x$ time interaction during the evolution over time were analyzed using two-way ANOVA. Bonferroni's correction for multiple comparisons was used with two-way ANOVA, and for five time point comparisons (baseline, post-shock, 1, 3, and $6 \mathrm{~h}$ ) significance was considered to be $P \leq 0.01$ for the three levels of the analysis (between, within and factor $x$ time interaction). The commercially available SPSS 10.0 (USA) statistical software package was used.

\section{Results}

\section{Shock period}

The cardiac balloon was initially inflated with $8.0 \pm 4.9$ $\mathrm{mL} / \mathrm{kg}$ of room air, and variations in the balloon volume were performed to keep the systemic ABPm within the preset range. Physiological data during the shock period are reported in Table 1.

During shock, transient cardiac tamponade induced a sustained decrease in cardiac index and mixed venous saturation, as well as an important increase in ileal $\mathrm{CO}_{2}$ $\mathrm{EtCO}_{2}$ gap. Lactate increased 4-fold during shock and standard base excess decreased consistently during shock (Table 1). These data are consistent with severe systemic hypoperfusion during cardiac tamponade. 
Table 1. Physiological data obtained during the cardiac tamponade shock period.

\begin{tabular}{|c|c|c|c|c|c|c|c|c|}
\hline Variable & Baseline & $10 \mathrm{~min}$ & $20 \mathrm{~min}$ & $30 \mathrm{~min}$ & $40 \mathrm{~min}$ & $50 \mathrm{~min}$ & $60 \min$ & Post-shock \\
\hline \multicolumn{9}{|c|}{ Balloon volume (mL/kg) } \\
\hline Control & 0 & 0 & 0 & 0 & 0 & 0 & 0 & 0 \\
\hline Shock & 0 & $8.0 \pm 4.9$ & $12.8 \pm 9.1$ & $13.5 \pm 5.5$ & $16.0 \pm 5.1$ & $16.6 \pm 7.4$ & $14.6 \pm 7.6$ & 0 \\
\hline \multicolumn{9}{|c|}{ Cardiac index $\left(\mathrm{mL} \cdot \mathrm{kg}^{-1} \cdot \mathrm{min}^{-1}\right)$} \\
\hline Control & $157 \pm 38$ & - & - & - & - & - & - & $149 \pm 21$ \\
\hline Shock & $152 \pm 37$ & $94 \pm 49$ & $77 \pm 37$ & $65 \pm 37$ & $66 \pm 31$ & $64 \pm 25$ & $63 \pm 20$ & $84 \pm 19$ \\
\hline \multicolumn{9}{|c|}{ Heart rate (bpm) } \\
\hline Control & $107 \pm 14$ & - & - & - & - & - & - & $101 \pm 9$ \\
\hline Shock & $103 \pm 2$ & $137 \pm 27$ & $153 \pm 35$ & $178 \pm 22$ & $193 \pm 14$ & $202 \pm 23$ & $202 \pm 29$ & $176 \pm 26$ \\
\hline \multicolumn{9}{|c|}{ ABPm $(\mathrm{mmHg})$} \\
\hline Control & $110 \pm 14$ & - & - & - & - & - & - & $114 \pm 7$ \\
\hline Shock & $110 \pm 17$ & $50 \pm 3$ & $49 \pm 5$ & $47 \pm 4$ & $49 \pm 3$ & $48 \pm 2$ & $49 \pm 3$ & $75 \pm 11$ \\
\hline \multicolumn{9}{|c|}{ PAPm $(\mathrm{mmHg})$} \\
\hline Control & $26 \pm 5$ & - & - & - & - & - & - & $27 \pm 6$ \\
\hline Shock & $28 \pm 4$ & $26 \pm 2$ & $27 \pm 3$ & $29 \pm 3$ & $29 \pm 3$ & $31 \pm 4$ & $31 \pm 3$ & $35 \pm 8$ \\
\hline \multicolumn{9}{|c|}{ CVP $(\mathrm{mmHg})$} \\
\hline Control & $9 \pm 3$ & - & - & - & - & - & - & $11 \pm 3$ \\
\hline Shock & $11 \pm 3$ & $14 \pm 5$ & $14 \pm 5$ & $14 \pm 6$ & $14 \pm 5$ & $15 \pm 5$ & $11 \pm 3$ & $11 \pm 3$ \\
\hline \multicolumn{9}{|c|}{ PAOP $(\mathrm{mmHg})$} \\
\hline Control & $11 \pm 4$ & - & - & - & - & - & - & $11 \pm 5$ \\
\hline Shock & $12 \pm 2$ & - & - & - & - & - & - & $11 \pm 3$ \\
\hline \multicolumn{9}{|l|}{$\mathrm{SvO}_{2}(\%)$} \\
\hline Control & $74 \pm 6$ & - & - & - & - & - & - & $72 \pm 5$ \\
\hline Shock & $73 \pm 8$ & $42 \pm 11$ & $41 \pm 7$ & $37 \pm 5$ & $40 \pm 5$ & $35 \pm 4$ & $37 \pm 7$ & $64 \pm 7$ \\
\hline \multicolumn{9}{|c|}{$\mathrm{EtCO}_{2}(\mathrm{mmHg})$} \\
\hline Control & $35 \pm 3$ & - & - & - & - & - & - & $38 \pm 2$ \\
\hline Shock & $38 \pm 2$ & $32 \pm 2$ & $31 \pm 5$ & $32 \pm 2$ & $34 \pm 2$ & $35 \pm 3$ & $37 \pm 4$ & $47 \pm 6$ \\
\hline \multicolumn{9}{|c|}{$\mathrm{SBE}(\mathrm{mEq} / \mathrm{L})$} \\
\hline Control & $1.2 \pm 1.6$ & - & - & - & - & - & - & $2.0 \pm 0.9$ \\
\hline Shock & $3.7 \pm 0.8$ & - & - & - & - & - & - & $-7.3 \pm 3.3$ \\
\hline \multicolumn{9}{|c|}{$\mathrm{PrCO}_{2}-\mathrm{EtCO}_{2}(\mathrm{mmHg})$} \\
\hline Control & $22 \pm 9$ & - & - & - & - & - & - & $23 \pm 9$ \\
\hline Shock & $20 \pm 6$ & $30 \pm 6$ & $39 \pm 9$ & $45 \pm 12$ & $48 \pm 16$ & $48 \pm 17$ & $49 \pm 18$ & $48 \pm 17$ \\
\hline \multicolumn{9}{|c|}{ Lactate (mmol/L) } \\
\hline Control & $1.8 \pm 1.5$ & - & - & - & - & - & - & $1.9 \pm 0.9$ \\
\hline Shock & $1.7 \pm 0.7$ & - & - & - & - & - & - & $8.0 \pm 2.2$ \\
\hline \multicolumn{9}{|c|}{ Urinary output $\left(\mathrm{mL} \cdot \mathrm{kg}^{-1} \cdot \mathrm{h}^{-1}\right)$} \\
\hline Control & $4.6 \pm 2.4$ & - & - & - & - & - & - & $3.0 \pm 1.4$ \\
\hline Shock & $3.7 \pm 1.4$ & - & - & - & - & - & - & $0.9 \pm 0.9$ \\
\hline
\end{tabular}

Data are reported as means $\pm S D$ for 5 domestic large female pigs in each group. A dash indicates that the data were not collected. $\mathrm{ABPm}=$ systemic mean arterial blood pressure; $\mathrm{PAPm}=$ mean pulmonary artery blood pressure; $\mathrm{CVP}=$ central venous pressure; $\mathrm{PAOP}=$ pulmonary artery oclusion pressure; $\mathrm{SvO}_{2}=$ oxygen mixed venous saturation; $\mathrm{EtCO}_{2}=$ end tidal $\mathrm{CO}_{2}$ pressure; $\mathrm{SBE}=$ standard base excess; $\left(\mathrm{PrCO}_{2}-\mathrm{EtCO}_{2}\right)=$ tissue-arterial $\mathrm{CO}_{2}$ gap. 


\section{Post-shock and 6-h observation period}

All physiological data of both groups are shown in Figures 1 to 3 and Table 2. The amount of lactated Ringer's solution received during the $6 \mathrm{~h}$ of observation, $1350 \pm 189$ $\mathrm{mL}$ for the shock group, was not statistically different from $1200 \pm 99 \mathrm{~mL}$ for the control group.

After tamponade, shock animals developed myocardial dysfunction lasting for $6 \mathrm{~h}$, as observed by statistically significant decrease in stroke index and left ventricular work index, as well as a significant increase in heart rate (Figure 1). Transitory shock also induced sustained pulmonary hypertension and a late significant increase in CVP when compared to control animals (Figure 2). Other signs of cardiovascular dysfunction were the reduction in systemic ABPm with time in the shock group (Figure 2) and a significant decrease in mixed venous saturation after 3 and $6 \mathrm{~h}$ of relief of tamponade in the shock group compared to baseline (Figure 3).

Transient cardiac tamponade also induced inflammatory disturbances. Pigs submitted to shock developed significant hyperthermia compared to controls (Figure 3). IL-6, a cytokine clearly related to inflammatory processes, was increased significantly after 3 and $6 \mathrm{~h}$ in cardiac tamponade animals compared to baseline, thus suggesting that inflammatory changes could be related to cardiogenic shock.

The anatomic macroscopic appearance of the lungs and heart at the end of the observation period was normal and similar in all animals.

\section{Discussion}

This study demonstrates, for the first time, that severe and transient cardiogenic shock-induced hypodynamic states are associated with posterior persistent cardiovascular dysfunction and induction of inflammatory disturbances. These data also emphasize the obvious need for prompt treatment of hypotension in cardiogenic and obstructive shock in order to avoid the generation of inflammatory mediators that can be associated with the develop-

Table 2. Physiologic data during the 6-h observation period after cardiac tamponade.

\begin{tabular}{|c|c|c|c|c|c|c|c|}
\hline Variable & Baseline & Post shock & $1 \mathrm{~h}$ & $3 \mathrm{~h}$ & $6 \mathrm{~h}$ & $P$ & $\begin{array}{l}\text { Factor-time } \\
\text { interaction }\end{array}$ \\
\hline \multicolumn{8}{|c|}{ PAOP (mmHg) } \\
\hline Control & $11 \pm 4$ & $11 \pm 5$ & $9 \pm 2$ & $9 \pm 2$ & $7 \pm 2$ & & \\
\hline Shock & $12 \pm 2$ & $11 \pm 3$ & $12 \pm 4$ & $10 \pm 1$ & $9 \pm 1$ & & - \\
\hline \multicolumn{8}{|c|}{$\mathrm{PO}_{2} / \mathrm{FiO}_{2}$ ratio } \\
\hline Control & $401 \pm 100$ & $413 \pm 72$ & $417 \pm 89$ & $342 \pm 59$ & $331 \pm 52$ & & \\
\hline Shock & $365 \pm 51$ & $296 \pm 60$ & $299 \pm 75$ & $301 \pm 63$ & $304 \pm 46$ & & - \\
\hline \multicolumn{8}{|c|}{$\mathrm{EtCO}_{2}(\mathrm{mmHg})$} \\
\hline Control & $35 \pm 3$ & $38 \pm 2$ & $37 \pm 2$ & $39 \pm 2$ & $38 \pm 4$ & & 0.461 \\
\hline Shock & $38 \pm 2$ & $47 \pm 6$ & $45 \pm 4$ & $41 \pm 2$ & $39 \pm 2$ & & - \\
\hline \multicolumn{8}{|c|}{$\mathrm{SBE}(\mathrm{mEq} / \mathrm{L})$} \\
\hline Control & $1.2 \pm 1.6$ & $2.2 \pm 0.9$ & $2.8 \pm 0.8$ & $2.1 \pm 0.8$ & $3.8 \pm 2$ & $<0.001$ & $<0.001$ \\
\hline Shock & $3.7 \pm 0.8$ & $-7.3 \pm 3.3$ & $-3.1 \pm 3.2$ & $1.8 \pm 2.1$ & $3.3 \pm 0.7$ & $<0.001$ & - \\
\hline \multicolumn{8}{|c|}{$\mathrm{PrCO}_{2}-\mathrm{EtCO}_{2}(\mathrm{mmHg})$} \\
\hline Control & $22 \pm 9$ & $23 \pm 9$ & $27 \pm 8$ & $29 \pm 11$ & $35 \pm 2$ & & 0.039 \\
\hline Shock & $20 \pm 6$ & $48 \pm 17$ & $35 \pm 4$ & $38 \pm 5$ & $28 \pm 9$ & & - \\
\hline \multicolumn{8}{|c|}{ Lactate (mmol/L) } \\
\hline Control & $1.8 \pm 1.5$ & $1.9 \pm 0.9$ & $1.4 \pm 0.5$ & $1.8 \pm 1.4$ & $1.5 \pm 0.6$ & $<0.001$ & $<0.001$ \\
\hline Shock & $1.7 \pm 0.7$ & $8.0 \pm 2.2$ & $5.6 \pm 2.4$ & $2.6 \pm 2.1$ & $1.6 \pm 0.1$ & $<0.001$ & - \\
\hline \multicolumn{8}{|c|}{ Urinary output $\left(\mathrm{mL} \cdot \mathrm{kg}^{-1} \cdot \mathrm{h}^{-1}\right)$} \\
\hline Control & $4.6 \pm 2.4$ & $3.0 \pm 1.4$ & $2.4 \pm 1.5$ & $3 \pm 1.6$ & $1.2 \pm 0.4$ & $<0.019$ & \\
\hline Shock & $3.7 \pm 1.4$ & $0.9 \pm 0.9$ & $0.6 \pm 0.4$ & $1 \pm 0.4$ & $1 \pm 0.4$ & $<0.033$ & - \\
\hline
\end{tabular}

Data are reported as means \pm SD for 5 domestic large female pigs in each group. A dash indicates that the data were not calculated. Control group data were analyzed by two-way between analysis ANOVA and shock group data were analyzed by two-way within analysis ANOVA. $\mathrm{PO}_{2} / \mathrm{FiO}_{2}$ denotes oxygen partial pressure over inspiratory oxygen fraction ratio. Other abbreviations are defined in the legend to Table 1. 
ment of multiple organ failure (18).

This cardiogenic shock-induced systemic low flow model was planned to reach an ABPm of $45-55 \mathrm{mmHg}$. As shown in Table 1, the values of ABPm were close to 50 $\mathrm{mmHg}$ during the shock period and hypotension was associated with an important reduction of stroke index. Signs of tissue hypoxia during and after the shock period are clearly indicated by high ileum partial pressure of $\mathrm{CO}_{2}-\mathrm{EtCO}_{2}$ gap, low $\mathrm{SvO}_{2}$ levels and hyperlactatemia associated with metabolic acidosis. On this basis, the efficacy of the model for causing a real period of cardiogenic shock is remarkable.

Cardiogenic shock is caused by decreased systemic cardiac output in the presence of adequate intravascular volume resulting in tissue hypoxia (1). In experimental studies of this condition in which no treatment is instituted, death is attributed to the progressive failure of the left ventricular pump to maintain cardiac output and systemic pressures (19). The fatal course of cardiogenic shock is traditionally ascribed to a so-called downward spiral of events associated with the activation of compensatory mechanisms, such as the sympathetic nervous system and the renin-angiotensin system, resulting in an increase in heart rate and contractility that raises myocardial oxygen demand and worsens myocardial ischemia, and vasoconstriction that increases myocardial afterload (20). However, Lim et al. (21) have described that $45 \%$ of patients admitted with cardiogenic shock to a mixed intensive care unit died with a normal cardiac index and low or normal
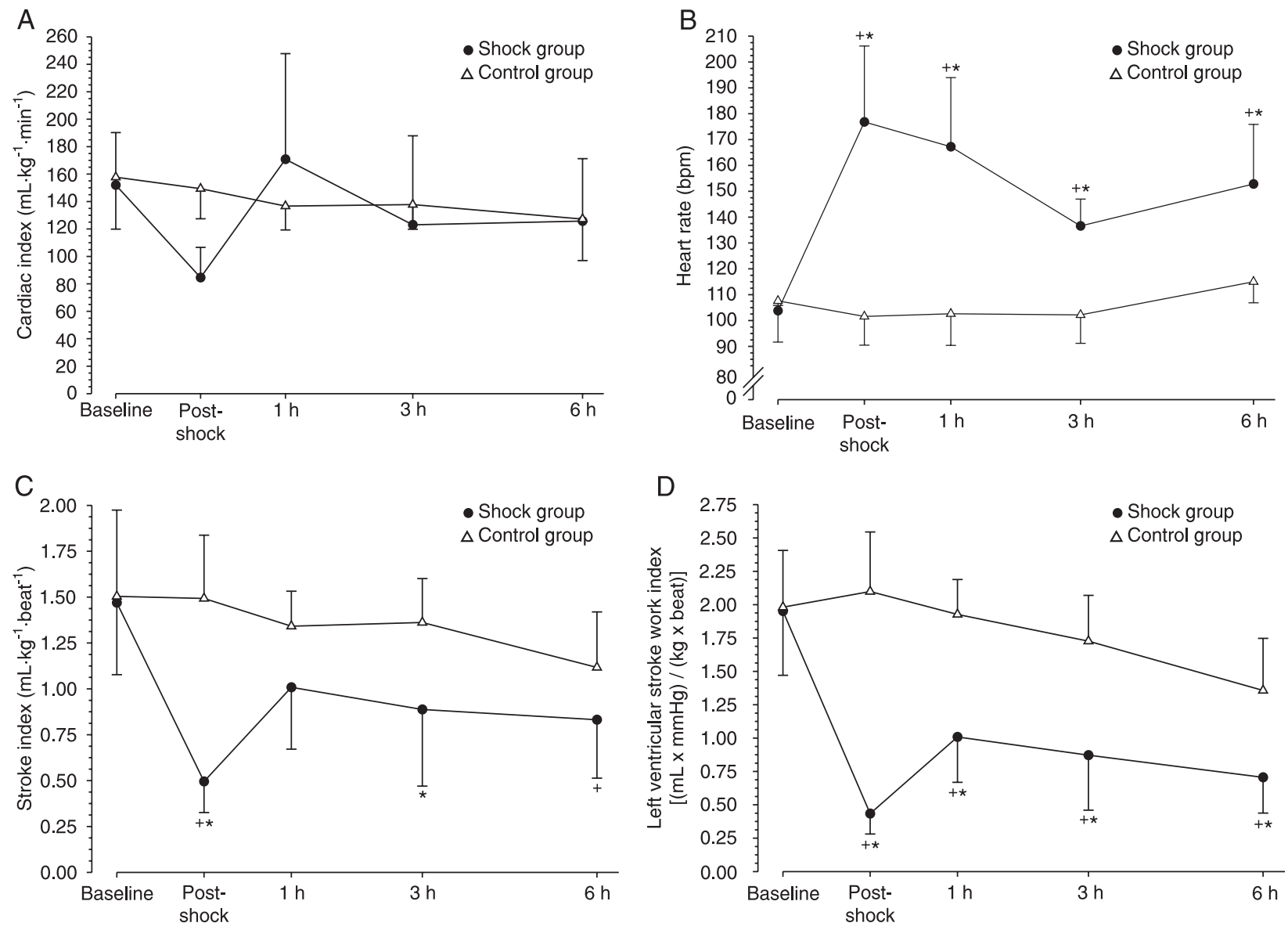

Figure 1. Evolution of hemodynamic parameters of pigs after cardiac tamponade shock. Filled circles = shock group; open triangles $=$ control group. Panel $A$, cardiac index (two-way ANOVA: $\mathrm{P}=0.378$, between analysis; $\mathrm{P}=0.186$, within analysis and $\mathrm{P}=0.148$, factor $x$ time interaction). Panel $B$, heart rate (two-way ANOVA: $P<0.001$, between analysis; $P<0.001$, within analysis and $P<0.001$, factor $x$ time interaction). Panel $C$, stroke index over time (two-way ANOVA: $P<0.001$, between analysis $x$ time interaction). Panel $D$, left ventricular stroke work index (two-way ANOVA: $P<0.001$, between analysis; $P<0.001$, within analysis and $P<0.001$, factor $x$ time interaction). Data are reported as means \pm SD for 5 pigs in each group. ${ }^{*} \mathrm{P}<0.05$ vs control group (Tukey post hoc analysis). ${ }^{+} \mathrm{P}$ $<0.05$ vs baseline (Tukey post hoc analysis). 
systemic vascular resistance index. Among those patients, only half of them had evidence of infection. The authors concluded that it could be necessary to reevaluate the spiral model of the fatal course of cardiogenic shock.

A large subgroup of patients with cardiogenic shock after myocardial infarction showed clinical signs of severe systemic inflammation (22), and those who were culture positive for sepsis had twice the risk of death (11). Observation of lower systemic vascular resistance at the onset of shock in patients who subsequently had culture-positive systemic inflammation suggests that inappropriate vasodilation may play an important role in the pathogenesis and persistence of shock $(2,11)$.
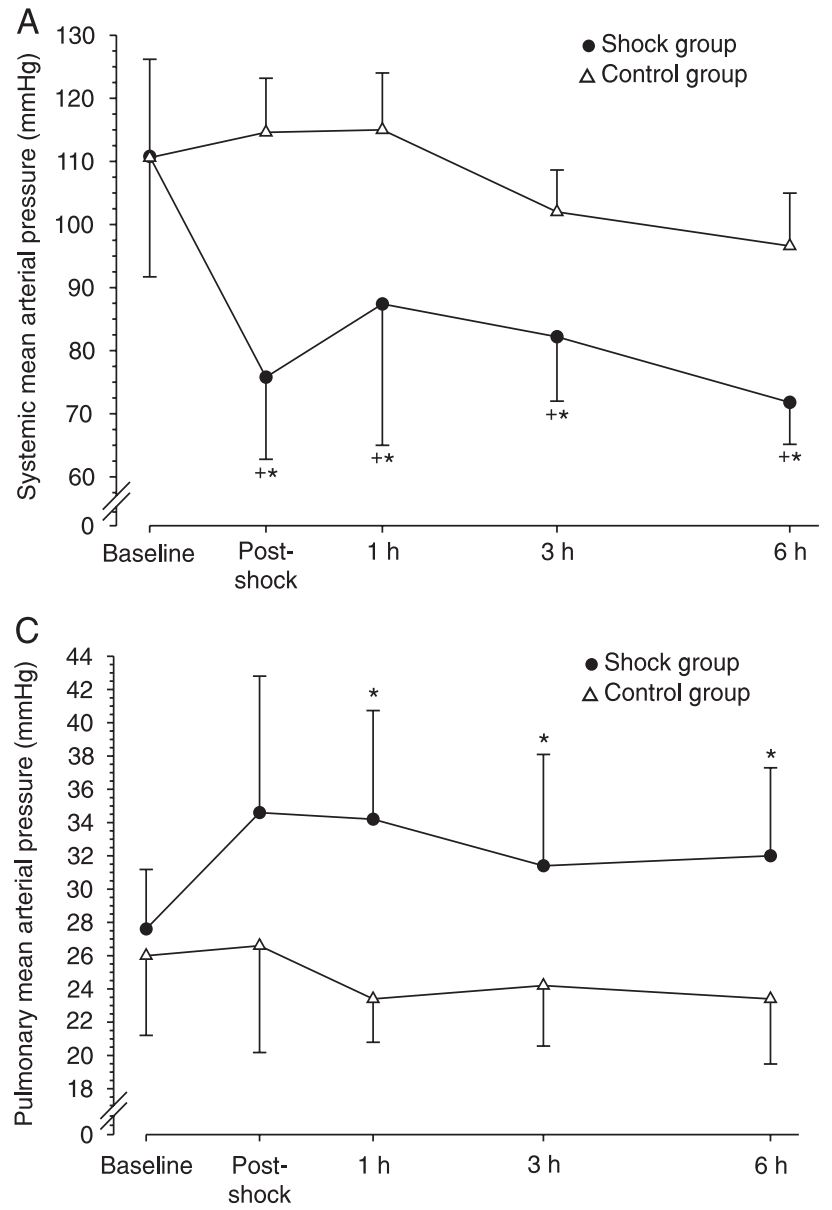

In the present study, the presence of relative hypotension with a preserved cardiac index points to vasodilatory shock. The absence of difference in the evolution of the calculated systemic vascular resistance index between the tamponade and control groups could be explained by a low severity vasodilation or by relative hypovolemia caused by the increase in systemic oxygen consumption and hyperthermia. The pathogenesis of vasodilation in cardiogenic shock has been attributed to the release of inflammatory cytokines with subsequent production of $\mathrm{NO}$ by inducible NOS (2). In some clinical studies, the development of SIRS criteria and the production of inflammatory mediators after cardiogenic shock have been associated with
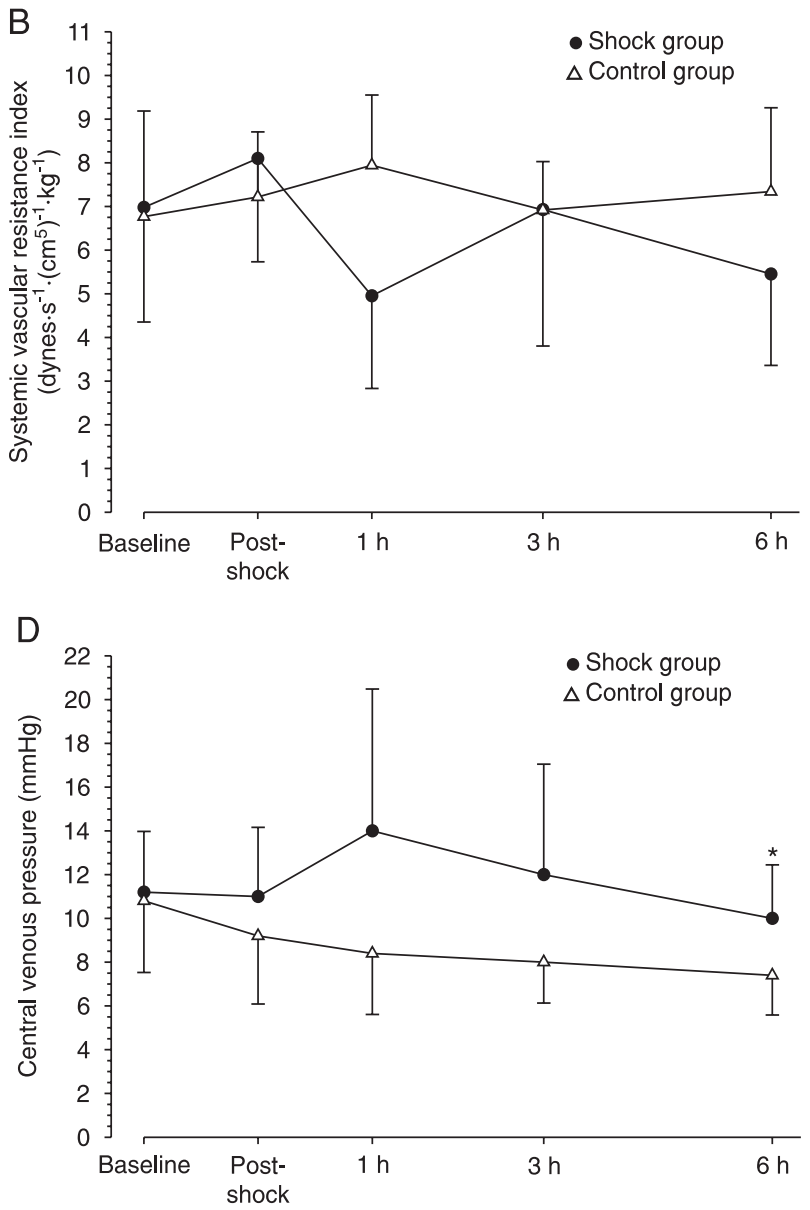

Figure 2. Systemic hemodynamic and perfusional features of pigs during the study. Filled circles = shock group; open triangles = control group. Panel $A$, systemic mean arterial pressure over time (two-way ANOVA: $\mathrm{P}<0.001$, between analysis; $\mathrm{P}<0.001$, within analysis and $P=0.029$, factor $x$ time interaction). Panel $B$, systemic vascular resistance index during the study (two-way ANOVA: $P$ $=0.223$, between analysis; $P=0.700$, within analysis and $P=0.252$, factor $x$ time interaction). Panel $C$, pulmonary mean arterial pressure over time (two-way ANOVA: $\mathrm{P}<0.001$, between analysis; $\mathrm{P}=0.589$, within analysis and $\mathrm{P}=0.422$, factor $\mathrm{x}$ time interaction). Panel $D$, central venous pressure (two-way ANOVA: $\mathrm{P}=0.007$, between analysis; $\mathrm{P}=0.545$, within analysis and $\mathrm{P}=0.536$, factor $\mathrm{x}$ time interaction). Data are reported as means \pm SD for 5 pigs in each group. ${ }^{*} \mathrm{P}<0.05$ vs control group (Tukey post hoc analysis). ${ }^{+} \mathrm{P}$ $<0.05$ vs baseline (Tukey post hoc analysis). 

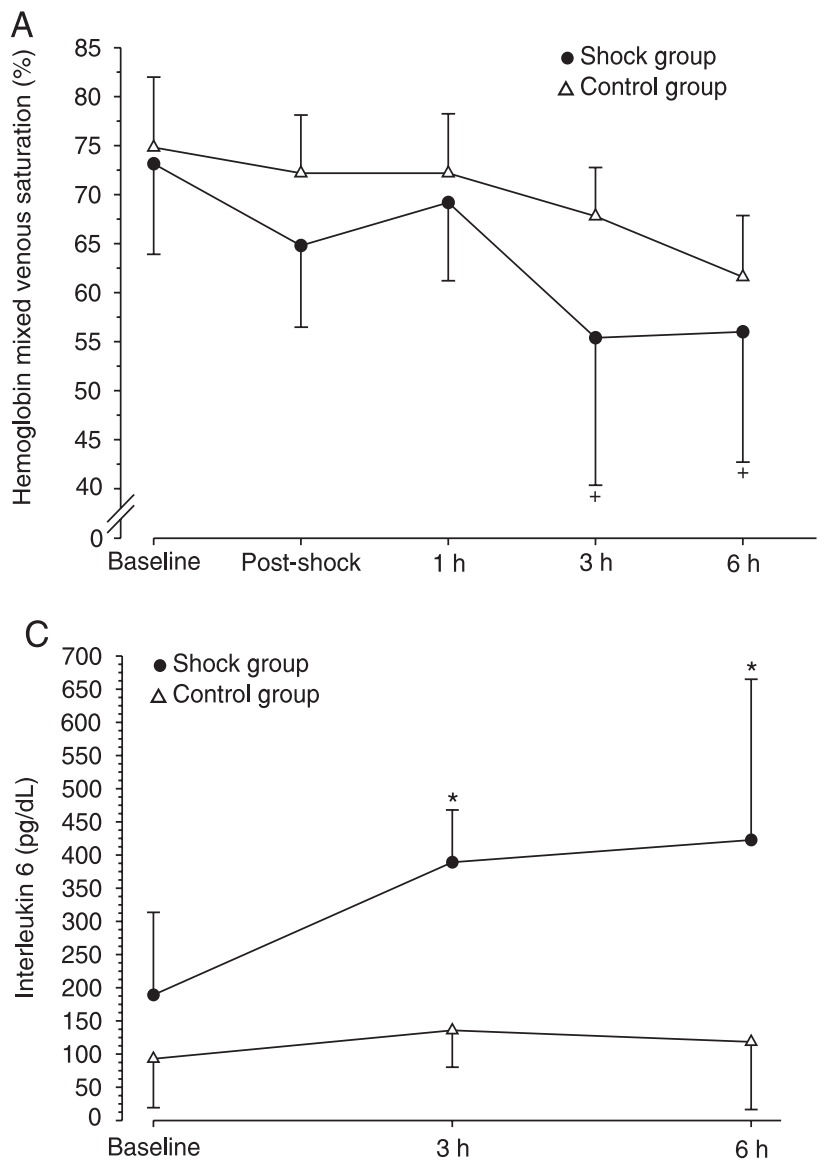

multiple organ failure and increased mortality $(11,12,18)$. However, there are few experimental studies supporting these clinical data and in clinical trials some bias may have affected the interpretation of the data. For instance, in the subgroup analysis of the SHOCK study, a significant number of patients reported with SIRS criteria were previously submitted to coronary artery bypass graft, a condition largely associated with inflammatory activation (11).

In this model, besides hypotension, a possible myocardial dysfunction marked by preserved cardiac index with elevated heart rate and low stroke index occurred, resulting in a low left ventricular stroke work index. It could be associated with the induced inflammatory syndrome (23). However, it is hard to affirm that inflammatory activation was the only factor responsible for this myocardial depression.

Other controversial results came from studies that evaluated NO role in this scenario. Unspecific NOS blockade was not able to restore cardiovascular function in experimental coronary microembolization (13) nor did its block-

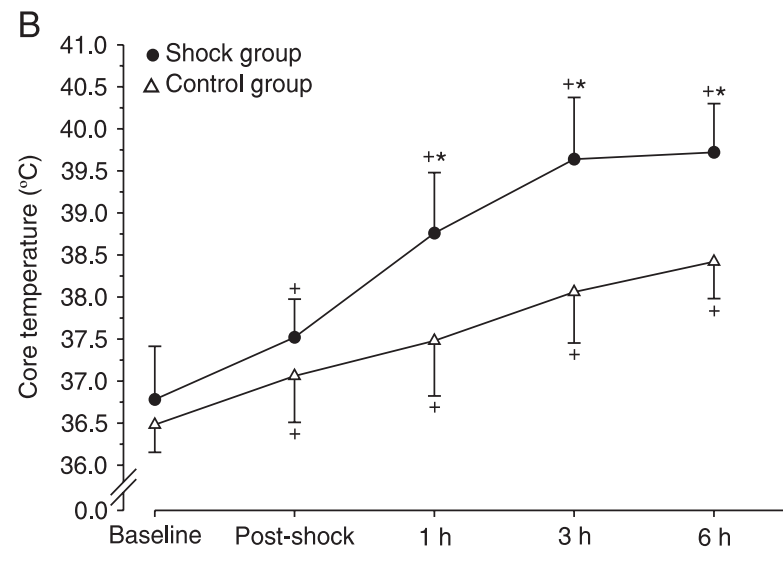

Figure 3. Perfusion and inflammatory features of pigs during the study. Filled circles $=$ shock group; open triangles $=$ control group. Panel $A$, hemoglobin mixed venous saturation over time (two-way ANOVA: $P=0.023$, between analysis; $P=0.002$, within analysis and $P=0.701$, factor $x$ time interaction). Panel $B$, core temperature over time (two-way ANOVA: $P=0.023$, between analysis; $P=0.002$, within analysis and $P=0.701$, factor $x$ time interaction). Panel $C$, serum concentration of interleukin 6 (two-way ANOVA: $P<0.001$, between analysis; $P<0.001$, within analysis and $P=0.070$, factor $x$ time interaction). Data are reported as means $\pm S D$ for 5 pigs in each group. ${ }^{*} P<0.05$ vs control group (Tukey post hoc analysis). ${ }^{+} \mathrm{P}<0.05$ vs baseline (Tukey post hoc analysis).

ade demonstrate any benefit in reducing the mortality in a large clinical study (5), despite previous results from small trials $(3,4)$. Our study demonstrates partially that the inflammatory response acts as a pathway associated with cardiogenic shock and adds new information by demonstrating that even transient hypotension is followed by prolonged vascular dysfunction. The controlled experimental setting of this study may also eliminate some of the bias observed in clinical trials and therefore may be useful for future studies of systemic hemodynamics and therapeutics in hypodynamic shock.

Our study has some limitations: First, the spleen was removed and it can be responsible for the modulation (amplification) of extra spleen cytokine production in dogs (24). Second, from the statistic viewpoint, many comparisons can be underpowered using two-way ANOVA with Bonferroni's correction for multiple comparisons. Third, the time spent in shock $(1 \mathrm{~h})$ may not have been sufficient to trigger a clinically important inflammatory response in order to cause absolute hypotension after shock. 


\section{References}

1. Hasdai D, Topol EJ, Califf RM, Berger PB, Holmes DR Jr. Cardiogenic shock complicating acute coronary syndromes. Lancet 2000; 356: 749-756.

2. Hochman JS. Cardiogenic shock complicating acute myocardial infarction: expanding the paradigm. Circulation 2003; 107: 2998-3002.

3. Cotter G, Kaluski E, Milo O, Blatt A, Salah A, Hendler A, et al. LINCS: L-NAME (a NO synthase inhibitor) in the treatment of refractory cardiogenic shock: a prospective randomized study. Eur Heart J 2003; 24: 1287-1295.

4. Cotter G, Kaluski E, Blatt A, Milovanov O, Moshkovitz Y, Zaidenstein $\mathrm{R}$, et al. L-NMMA (a nitric oxide synthase inhibitor) is effective in the treatment of cardiogenic shock. Circulation 2000; 101: 1358-1361.

5. Alexander JH, Reynolds HR, Stebbins AL, Dzavik V, Harrington RA, Van de Werf $F$, et al. Effect of tilarginine acetate in patients with acute myocardial infarction and cardiogenic shock: the TRIUMPH randomized controlled trial. JAMA 2007; 297: 1657-1666.

6. Hochman JS, Sleeper LA, Webb JG, Sanborn TA, White $\mathrm{HD}$, Talley JD, et al. Early revascularization in acute myocardial infarction complicated by cardiogenic shock. SHOCK Investigators. SHould we emergently revascularize Occluded Coronaries for cardiogenic shock. N Engl J Med 1999; 341: 625-634.

7. Sanborn TA, Sleeper LA, Bates ER, Jacobs AK, Boland J, French JK, et al. Impact of thrombolysis, intra-aortic balloon pump counterpulsation, and their combination in cardiogenic shock complicating acute myocardial infarction: a report from the SHOCK Trial Registry. SHould we emergently revascularize Occluded Coronaries for cardiogenic shock? J Am Coll Cardiol 2000; 36: 1123-1129.

8. Dens J, Dubois C, Ector H, Desmet W, Janssens S. Survival of patients treated with intra-aortic balloon counterpulsation for cardiogenic shock in a tertiary centre: variables correlated with death. Eur J Emerg Med 2003; 10: 213-218.

9. Carnendran L, Abboud R, Sleeper LA, Gurunathan R, Webb $J G$, Menon V, et al. Trends in cardiogenic shock: report from the SHOCK Study. The SHould we emergently revascularize Occluded Coronaries for cardiogenic shock? Eur Heart J 2001; 22: 472-478.

10. Kitashiro S, Sugiura T, Tamura T, Izuoka T, Miyoshi H, Saito $D$, et al. Factors associated with increased extravascular lung water in cardiac tamponade and myocardial ischemia. Crit Care Med 1999; 27: 2229-2233.

11. Kohsaka S, Menon V, Lowe AM, Lange M, Dzavik V, Sleeper LA, et al. Systemic inflammatory response syndrome after acute myocardial infarction complicated by car- diogenic shock. Arch Intern Med 2005; 165: 1643-1650.

12. Geppert A, Dorninger A, Delle-Karth G, Zorn G, Heinz G, Huber K. Plasma concentrations of interleukin-6, organ failure, vasopressor support, and successful coronary revascularization in predicting 30-day mortality of patients with cardiogenic shock complicating acute myocardial infarction. Crit Care Med 2006; 34: 2035-2042.

13. Nordhaug D, Steensrud T, Aghajani E, Korvald C, Myrmel $T$. Nitric oxide synthase inhibition impairs myocardial efficiency and ventriculo-arterial matching in acute ischemic heart failure. Eur J Heart Fail 2004; 6: 705-713.

14. Hannon JP, Bossone CA, Wade CE. Normal physiological values for conscious pigs used in biomedical research. $L a b$ Anim Sci 1990; 40: 293-298.

15. Hannon JP, Bossone CA, Rodkey WG. Splenic red cell sequestration and blood volume measurements in conscious pigs. Am J Physiol 1985; 248: R293-R301.

16. Hoit BD, Gabel M, Fowler NO. Influence of splenectomy on hemodynamics during cardiac tamponade. Am J Physiol 1991; 261: R907-R911.

17. Ginosar $Y$, Pizov R, Sprung CL. Arterial and pulmonary artery catheters. In: Parrillo JE, Bone RC (Editors), Critical care medicine: Principles of diagnosis and management. St. Louis: Mosby-Year Book, Inc.; 1995. p 25-49.

18. Geppert A, Steiner A, Zorn G, Delle-Karth G, Koreny M, Haumer $M$, et al. Multiple organ failure in patients with cardiogenic shock is associated with high plasma levels of interleukin-6. Crit Care Med 2002; 30: 1987-1994.

19. Lluch S, Moguilevsky HC, Pietra G, Shaffer AB, Hirsch LJ, Fishman AP. A reproducible model of cardiogenic shock in the dog. Circulation 1969; 39: 205-218.

20. Hollenberg SM. Cardiogenic shock. Crit Care Clin 2001; 17 : 391-410.

21. Lim N, Dubois MJ, De Backer D, Vincent JL. Do all nonsurvivors of cardiogenic shock die with a low cardiac index? Chest 2003; 124: 1885-1891.

22. Brunkhorst FM, Clark AL, Forycki ZF, Anker SD. Pyrexia, procalcitonin, immune activation and survival in cardiogenic shock: the potential importance of bacterial translocation. Int J Cardiol 1999; 72: 3-10.

23. Rudiger A, Singer M. Mechanisms of sepsis-induced cardiac dysfunction. Crit Care Med 2007; 35: 1599-1608.

24. Moeniralam HS, Bemelman WA, Endert E, Koopmans R, Sauerwein HP, Romijn JA. The decrease in nonsplenic interleukin-6 (IL-6) production after splenectomy indicates the existence of a positive feedback loop of IL-6 production during endotoxemia in dogs. Infect Immun 1997; 65: 22992305. 